\title{
Constitutive and cytokine induced expression of HLA molecules, secretory component, and intercellular adhesion molecule- 1 is modulated by butyrate in the colonic epithelial cell line HT-29
}

\author{
D Kvale, P Brandtzaeg
}

\begin{abstract}
Normal colonic epithelial cells play an important part in the mucosal immune system and use butyrate, a bacterial fermentation product, as an important energy source. Butyrate deficiency has been associated with inflammatory bowel disease, diversion colitis, and pseudomembranous colitis. Butyrate effects on important molecules for epithelial immune functions were studied in a colonic epithelial cell line (HT-29): the constitutive and cytokine regulated expression of secretory component (polyIg receptor), HLA class I and II molecules, and intercellular adhesion molecule-1 (ICAM-1). Butyrate facilitated the constitutive expression of secretory component and HLA class I. Butyrate furthermore tended to enhance cytokine mediated stimulation of protein expression, although tumour necrosis factor $\alpha$ (TNF) and interleukin 4 (IL 4) responses on HLA class $I$ and secretory component, respectively, were relatively inhibited by butyrate. Cytokine mediated accumulation in the various mRNAs usually increased even more in the presence of butyrate, with the exception of TNF response on HLA class I and secretory component mRNA concentrations. In conclusion, butyrate may substantially influence constitutive and cytokine mediated expression of molecules with immune functions in a complex and differentiated manner, and butyrate deficiencies, as seen in various clinical conditions, might influence mucosal immune responses.
\end{abstract} (Gut 1995; 36: 737-742)

Section for Clinical Immunology and Infectious Diseases, Medical Department A D Kvale

and Laboratory for Immunohistochemistry and Immunopathology, Institute of Pathology, University of Oslo, The National Hospital, Rikshospitalet, Oslo,

Norway

P Brandtzaeg

Correspondence to: Dr D Kvale, Medica Department A,

Rikshospitalet, N-0027 Oslo, Norway.

Accepted for publication

7 September 1994

adhesion molecule-1, colonic epithelial cell line.

Short chain fatty acids are the predominant aqueous solutes of normal human stool, amounting to a total concentration of 100 to $240 \mathrm{mM}$. Short chain fatty acids mainly consist of acetic, propionic, and butyric acids, which are fermentation products from anaerobic bacteria in the large bowel. ${ }^{1}$ Butyric acid, accounting for about $17 \%$ of the short chain fatty acids, cannot be produced by human cells but nevertheless seems to be the most important energy source for colonic epithelial cells in normal conditions. ${ }^{2-4}$
Decreased availability ${ }^{5-7}$ or impaired oxidation $^{3}$ of short chain fatty acids and particularly butyrate might be associated with development of ulcerative colitis and diversion colitis. It has been speculated whether low butyrate consumption represents a metabolic failure that may, at least partly, explain the pathogenesis of ulcerative colitis. ${ }^{3}$ The possibility exists, however, that low consumption, if present, merely reflects enzymatic changes over time secondary to low butyrate concentrations with the gut lumen. It should be noted that two recent reports $^{48}$ found no differences between patients with ulcerative colitis and controls when butyrate metabolism was measured in biopsy specimens. Thus, it seems that decreased supply of butyrate might be the factor participating in the pathogenesis of colitis.

Luminal butyrate deficiency probably evolves from shifts within the colonic bacterial flora, either spontaneously or after consumption of various antibiotics. ${ }^{9}$ It is noteworthy that enemas containing faeces from healthy donors, ${ }^{1011}$ possibly by reintroducing butyrate producing strains, or butyrate enemas $^{67}$ can induce clinical improvement of ulcerative colitis, pseudomembranous enterocolitis, and diversion colitis. Moreover, taking into account the profound effects of butyrate in regulating the behaviour of cells in vitro, ${ }^{12}$ it might be speculated that differences in the luminal butyrate concentration itself can change several functions of the colonic mucosal barrier. Because immunological properties of intestinal epithelial cells have been extensively studied by our laboratory (for review, see reference 13) as well as their modulations by cytokines, ${ }^{14-16}$ we wanted to study the effects of butyrate to this end in a well characterised experimental system.

The human colonic adenocarcinoma cell line HT-29m3 was used. These cells were subcloned from the HT-29m2 cell line previously selected for high expression of secretory component. ${ }^{17}$ The cells were grown in 96 well microplates (Falcon, Lincoln Park, NJ) at $37^{\circ} \mathrm{C}$ with $5 \% \quad \mathrm{CO}_{2}$ in minimal essential medium (Flow Laboratories, Irvine, Scotland) containing $10 \%$ heat inactivated fetal calf 
serum (Gibco, Grand Island, NY) and penicillin, streptomycin and amphotericine B (Gibco). Testing for Mycoplasma infection was regularly performed.

\section{Antibodies}

The following monoclonal antibodies (mAbs) and polyclonal antibody reagents were used: (a) $\mathrm{mAb}$ to human secretory component (ascites at $1 / 1800$ dilution) ${ }^{17}$; (b) $\mathrm{mAb}$ to HLA class I (clone W6/32, ascites at $1 / 3000$ (Sera Lab, Sussex, UK)); (c) mAb to human HLA-DR (clone L243, at $1 / 1600$ (Becton Dickinson, Sunnyvale, CA)); and (d) $\mathrm{mAb}$ to human ICAM-1 (clone 84H10, purified IgG $0.25 \mu \mathrm{g} / \mathrm{ml}$ (Serotec, Oxford, UK)); (e) rabbit antimouse IgG (purified IgG at $1 / 800$ dilution (Dakopatts, Glostrup, Denmark)); and (f) peroxidase conjugated swine antirabbit IgG (1/3000 dilution (Dakopatts)). A control $\mathrm{mAb}$ to an Aspergillus enzyme (Dakopatts) was used as purified IgG at $1 \mu \mathrm{g} / \mathrm{ml}$ to control for non-specific binding of primary reagents.

\section{Reagents}

Recombinant human interferon $\gamma$ (IFN), tumour necrosis factor (TNF), interleukin $1 \beta$ (IL 1), and IL 4 were purchased from Genzyme (Boston, MA). Individual cytokine activity was defined in international units (IU) according to standard procedures performed by the manufacturers. Sodium butyrate was purchased from Sigma (St Louis, MO).

Two antisense 35-mer DNA oligonucleotide probes were purchased from Genosys (Houston TX): (a) HLA class I consensus regions were first determined from available gene sequences in the GenEMBL database to design a probe complementary to exon 4 encoding amino acids 212 to 223 of the $\alpha 3$ domain (5'-TGGTCCTCSCCATCCCGCTGCCAGGTCAGTGTGAT- ${ }^{\prime}$ ') using OLIGO Primer Analysis Program (National Biosciences, Hamel, MN). This particular sequence was compared with other human sequences in GenEMBL database to ensure its specificity for HLA class I. (b) An antisense probe for ICAM-1 was selected from the human CDNA by the OLIGO program sequence; it represented the base positions 894 to 928.16 Both these two antisense DNA probes were radiolabelled with $\gamma{ }^{32}$ P-dATP using T4 DNA polynucleotide kinase according to Sambrook et al ${ }^{18}$ before hybridisation with slot blots or northern blots.

Two 27-mer HLA-DR $\beta$ polymerase chain reaction DNA primers (GH46 and GH50 (Perkin Elmer, Norwalk, CT)) encoding a region within the second exon were used according to the manufacturer's instructions to generate a 272 base pair dsDNA product from total DNA of HT-29m 3 cells. This probe was purified and labelled with $\alpha$ ${ }^{32} \mathrm{P}-\mathrm{dCTP}$ along with cDNA probes representing human secretory component and $\beta$-actin, as described in detail elsewhere. ${ }^{16}$
Quantitative cellular enzyme linked immunosorbent assay (CELISA) for HLA class I, HLA class II, secretory component, and ICAM- 1 expression

CELISA performed on monolayers of fixed HT-29m3 as the solid phase has been described in detail elsewhere. ${ }^{16}$ In brief, antigen expression by fixed adherent cells was measured after primary labelling with mAbs followed by sequential incubations with rabbit antimouse IgG and peroxidase conjugated swine antirabbit IgG. The peroxidase dependent colour reaction was then measured as optical density (OD) at $492 \mathrm{~nm}$. The actual cell counts for all wells were subsequently determined at $\mathrm{OD}_{550 \mathrm{~nm}}$ after crystal violet staining of the same microplate. ${ }^{16}$

The following modifications were introduced to render the assays quantitative: reference cells (IFN and TNF stimulated HT-29m 3 cells, $50 \mathrm{IU} / \mathrm{ml}$ of each cytokine for 24 hours) expressing high antigen values were grown at graded densities on each microplate. These standard cells were given an arbitrary value of 1000 units of each antigen per cell. A standard curve for each microplate was obtained from the reference wells by plotting CELISA $\mathrm{OD}_{492 \mathrm{~nm}}$ values against the corresponding cell counts determined by crystal violet at $\mathrm{OD}_{550 \mathrm{~nm}}$. The Pearson correlation coefficients $(r)$ in log-log standard plots were usually above $0 \cdot 85$. The antigen content in each test well was calculated from this standard curve by means of linear regression analysis; the amount of antigen per cell could finally be determined by correcting for the cell count expressed as $\mathrm{OD}_{550 \mathrm{~nm}}$ in the actual test well.

Results of experiments from each test point were obtained as medians of quadruplicate measurements; differences between quadruplicates was tested by the two tailed MannWhitney U test. All CELISA microplates included both irrelevant control $\mathrm{mAb}$ and standard background OD without primary antibody. All experiments were repeated at least twice.

\section{Slot blot and northern blot analysis}

Total RNA from HT-29m 3 cells was prepared from cells that had been detached by rubber policeman, pelleted, and subsequently snap frozen in liquid nitrogen. The isolation of RNA by the guanidium isothiocyanate method and the preparation of slot blots and northern blots have been described in detail previously. ${ }^{16}$ Densitometric analyses of suitably exposed slot blot autoradiograms were analysed for OD by a 2202 Ultroscan Laser Densitometer (LKB, Bromma, Sweden).

\section{Results}

Effects of butyrate on cell growth and morphology Butyrate inhibited cell growth in a dose dependent manner, depending on the incubation time; after four days growth inhibition was about $25 \%$ for butyrate concentrations at 
Figure 1: Dose dependent responses to butyrate. Quantitative CELISA results for HLA class I, $H L A$ class II, secretory component, and ICAM-1 after incubation (four days) with butyrate at various concentrations (solid lines) and after coincubation with IFN (50 IU/m) and TNF (50 IU/ml) for the last 24 hours (ICAM-1) or 48 hours (HLA molecules and secretory component) (broken lines). Each data point represents the median cellular expression

(quadruplicate wells) in relation to reference cells assigned an arbitrary value of $1000 \mathrm{U}$. The decrease in HLA class I expression obtained with $0.5 \mathrm{mM}$ butyrate was consistent in three different experiments. Vertical lines indicate the 25 and 75 non-parametric rank percentiles. The results of control cells appear in the data set where

butyrate $=0 \mathrm{mM}$. The differences between cells treated with butyrate alone or combinations of butyrate, IFN, and TNF, were statistically different at each data point $(p=0.02)$.
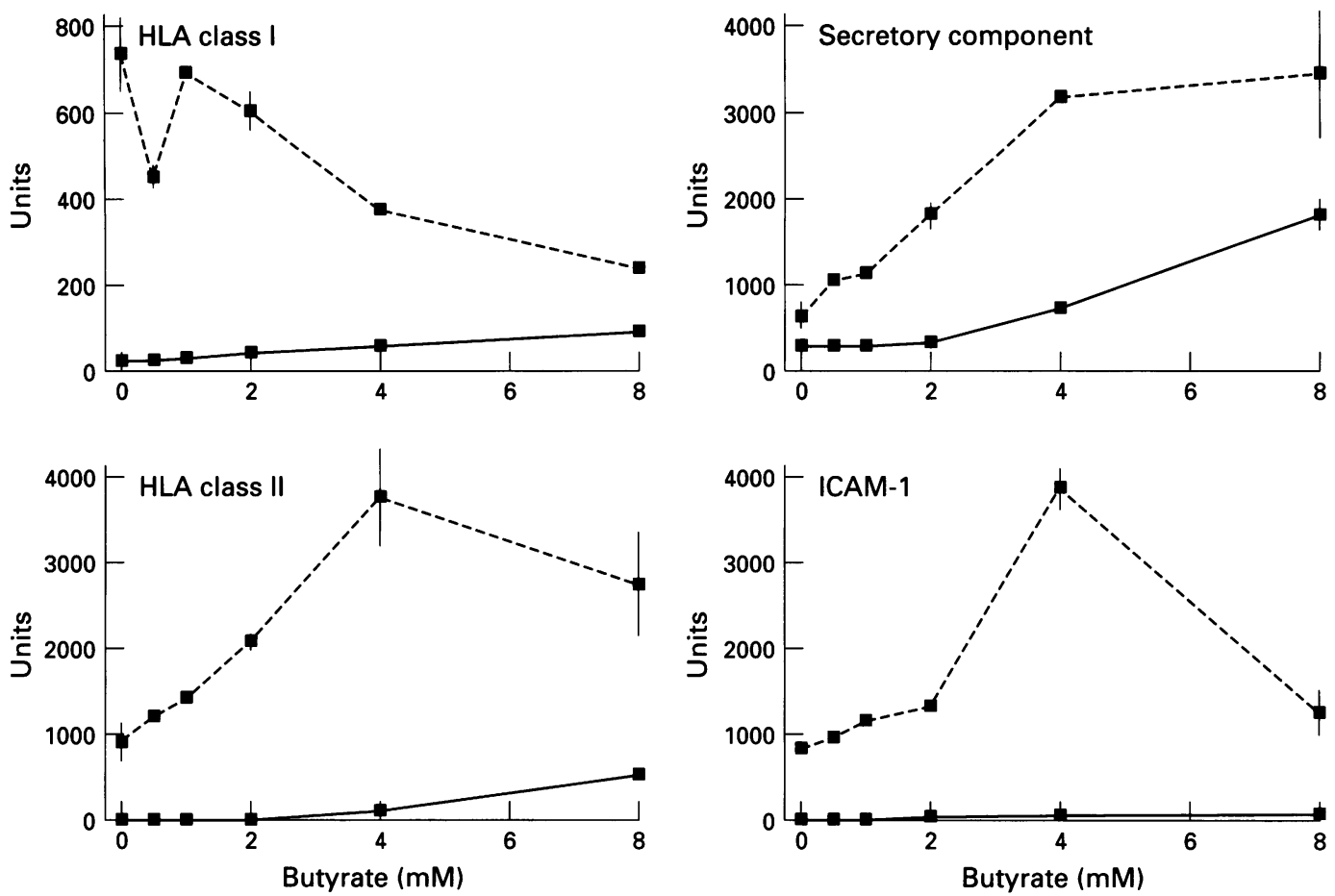

$4 \mathrm{mM}$ and lower, increasing to about $75 \%$ at $8 \mathrm{mM}$. The growth was further inhibited by about $10-15 \%$ when IFN, TNF, or IL 1 was coincubated to $100 \mathrm{IU} / \mathrm{ml}$ with butyrate, and even more so when combinations of these cytokines were used (data not shown). The morphology of the cells was mainly intact during these short term incubations with butyrate. A minor fraction of the cells developed time dependent accumulation of small mucin droplets as described by others. ${ }^{19}$ The viability of adherent cells after the final rinse immediately
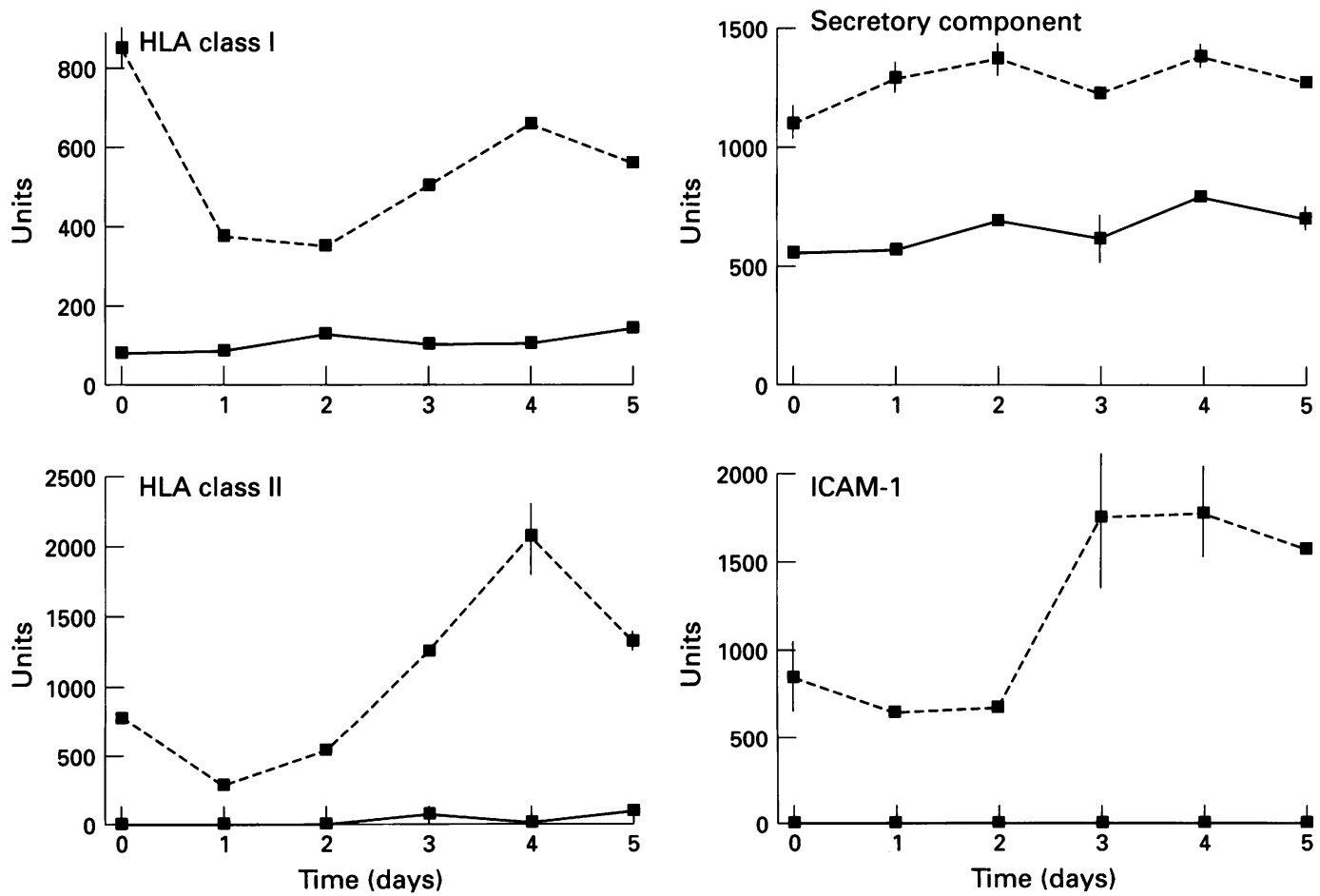

Figure 2: Kinetics of butyrate mediated effects. Quantitative CELISA results for $H L A$ class I, $H L A$ class II, secretory component, and ICAM-1 after incubation with $3 \mathrm{mM}$ butyrate for one to five days (solid lines) and after coincubation with IFN (50 IU/ml) and TNF (50 IU/ml) for the last day (broken lines) at every time point. Each point represents the median cellular concentration for quadruplicate wells. Vertical lines indicate the 25 and 75 non-parametric rank percentiles. The results of control cells appear in the data set where time $=0$ days. The differences between cells treated with butyrate alone or combinations of butyrate, IFN, and TNF, were statistically different at each data point $(p=0 \cdot 02)$. 
Figure 3: Butyrate modulation of the effects exerted by several cytokines and cytokine combinations. Quantitative CELISA results for $H L A$ class $I$, HLA class II, secretory component, and ICAM-1 in the absence (open columns) or presence (filled columns) of butyrate $3 \mathrm{mM}$ for 84 hours. Over the last 36 hours of the experiment the cells were also stimulated with IFN (100 $I U / \mathrm{ml})$, TNF (100 $\mathrm{IU} / \mathrm{ml}), \mathrm{IL} 1(200 \mathrm{IU} / \mathrm{ml})$, IL $4(200 \mathrm{IU} / \mathrm{ml})$, or various combinations of these cytokines. Each column represents the median cellular expression (quadruplicate wells) in relation to reference cells assigned an arbitrary value of $1000 \mathrm{U}$. Vertical lines indicate the 25 and 75 non-parametric rank percentiles. The results of control cells appear in the left most data set (0, open columns).
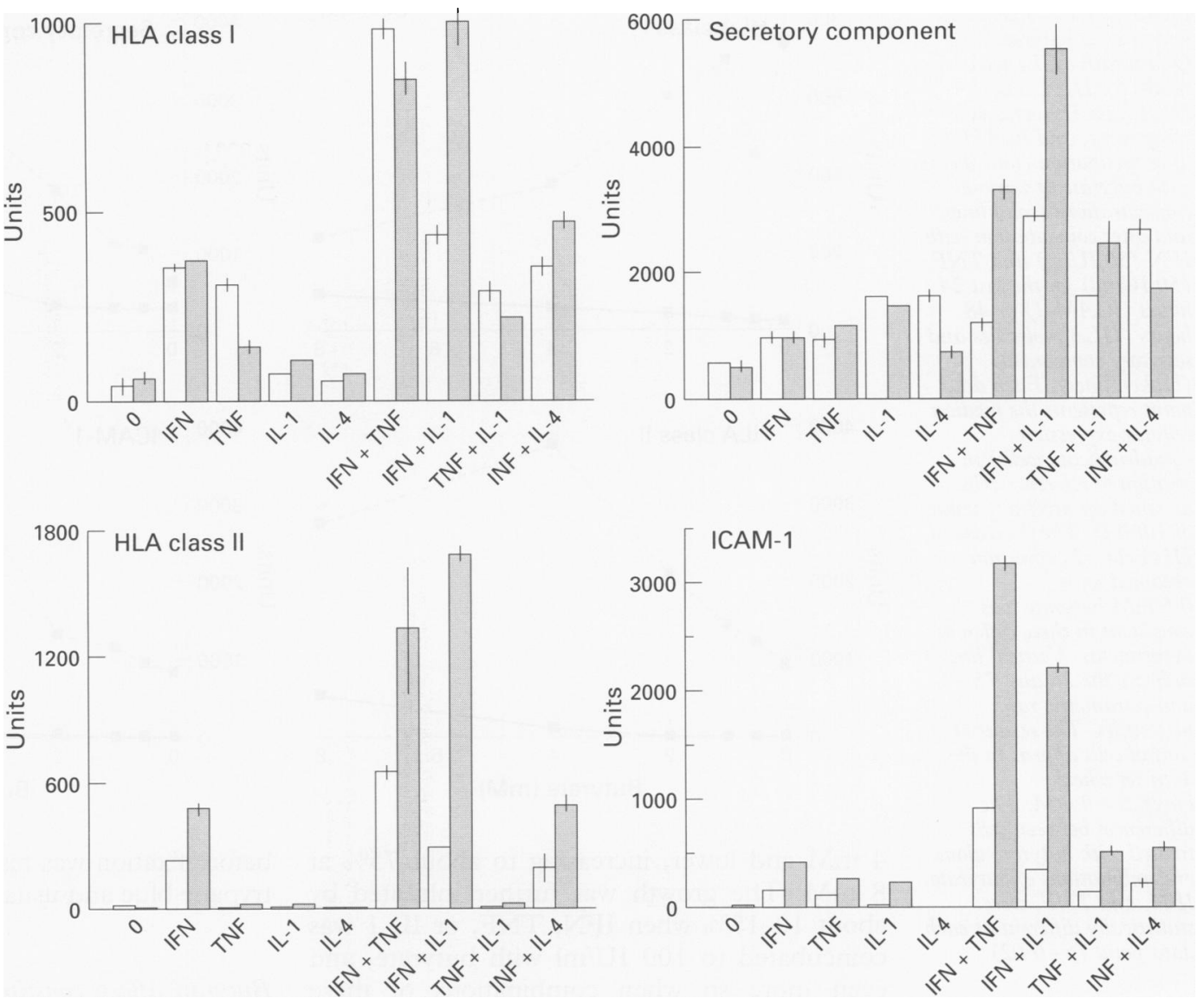

concentrations of butyrate showed a two to fourfold dose dependent increase in the constitutive secretory component and HLA class I expression. HLA class II molecules were undetectable in controls as well as butyrate stimulated cells, although a very weak de novo expression took place with butyrate at $8 \mathrm{mM}$. Constitutive ICAM-1 expression was quite low and was not enhanced by butyrate alone (Fig 1).

When we simultaneously tested whether preincubation of butyrate changed the response to a combination of the two proinflammatory cytokines IFN and TNF, all four immune markers were increased by cytokines as expected from previous experiments. ${ }^{14-16}$ However, butyrate modulated the cytokine mediated responses in different ways: secretory component expression was further enhanced; HLA class II and ICAM-1 expression was maximally increased at $4 \mathrm{mM}$; and HLA class I expression was reduced (Fig 1).

\section{Kinetics of the butyrate effects and butyrate modulated cytokine responses}

HT-29m 3 cells treated with $3 \mathrm{mM}$ butyrate alone from one to five days showed a minimal increase of HLA class I and secretory component expression over time, whereas the HLA class II and ICAM-1 values remained negative (Fig 2). After coincubation of IFN and TNF (both at $50 \mathrm{IU} / \mathrm{ml}$ ) with butyrate for the last day, the cytokine mediated effects on antigen expression were differentially modulated over time: considerable enhancement of HLA class II and ICAM-1; slight enhancement of secretory component; and a comparative reduction of HLA class I (Fig 2).

Effects of IL 1, IL 4, IFN, and TNF are differentially modulated by butyrate

HT $-29 \mathrm{~m} 3$ cells were preincubated with $3 \mathrm{mM}$ butyrate for 60 hours followed by 36 hours coincubation of butyrate and various cytokines alone or in combinations. Figure 3 shows the overall results of these experiments. The general trend was that butyrate further enhanced the cytokine induced increase of HLA class I, HLA class II, secretory component, and ICAM-1 but with two exceptions: (a) coincubation with butyrate selectively decreased the enhancement of HLA class I expression caused by TNF even in the presence of other cytokines; and (b) the enhancement of secretory component expression caused by IL 4, even along with IFN, was decreased in the presence of butyrate.

Butyrate modulates cytokine mediated changes in $m R N A$ values for HLA class I, HLA class II, secretory component, and ICAM-1

The two oligonucleotide antisense probes were tested on northern blots of total RNA from IFN stimulated HT-29m 3 cells: the HLA class I probe detected one band at approximately $1.5 \mathrm{~kb}$; and the ICAM-1 probe detected two bands (a strong $3.5 \mathrm{~kb}$ band and a much weaker $2.5 \mathrm{~kb}$ band) identical to those obtained after hybridisation with the original human ICAM-1 cDNA probe ${ }^{20}$ (data not shown).

RNA was isolated from control HT-29m3 cells and cells incubated with $3 \mathrm{mM}$ butyrate 

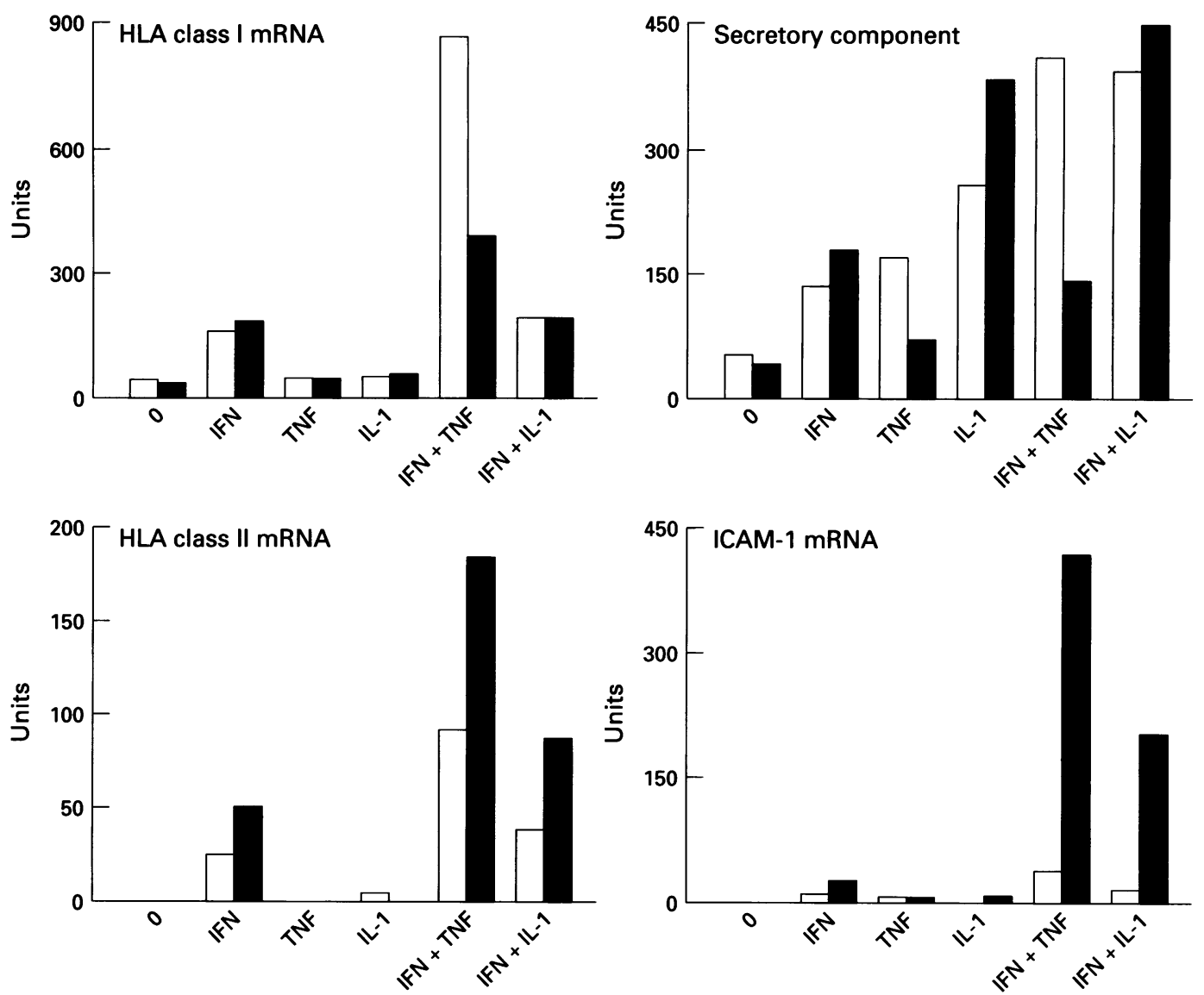

Figure 4: Butyrate effects on $m R N A$ concentrations. Quantitation of specific $m R N A$ in $H T-29 m 3$ cells treated in the absence (open columns) or presence (filled columns) of butyrate over 96 hours and various cytokines the last 24 hours as indicated in the text. Data were obtained by densitometric analyses of slot blots hybridised with the relevant DNA probes and are expressed in arbitrary units. mRNA concentrations of $\beta$-actin were virtually identical in all blots (data not shown).

over four days in combination with IFN, TNF, IL 1 , IFN and TNF, or IFN and IL 1 (100 IU/ml of each cytokine) on the last day (Fig 4). Densitometric analyses of slot blots hybridised with the various DNA probes showed that constitutive values of mRNA for HLA class I and secretory component were virtually unaffected by butyrate. Conversely, butyrate enhanced the IFN mediated increase in message for all four antigens, although it reduced to about $50 \%$ the enhancement of HLA class I and secretory component caused by IFN in combination with TNF (Fig 4). The blots were finally hybridised with the $\beta$-actin DNA probe showing fairly equal loading in the gels of total RNA (data not shown).

\section{Discussion}

The aim of this study was to examine how butyrate modulates different immunological functions of intestinal epithelial cells in a well characterised in vitro test system using HT-29 colonic cell lines. ${ }^{14-16}$ The study seemed relevant for two reasons. Firstly, clinical data have shown the association between changed butyrate metabolism and putative immunological diseases like ulcerative colitis. Secondly, the large bowel mucosa is the only tissue that is substantially exposed to butyrate in vivo under normal conditions.

It should be noted that butyrate has previously been reported to induce differentiation in the HT-29 cell line. ${ }^{21}$ We (unpublished findings) and others ${ }^{21}$ have even isolated
HT-29 subclones with permanently changed differentiation after longterm incubation with butyrate. Such profound morphological and phenotypical changes, however, did not appear during the incubation times used in these experiments. Nevertheless, most functional studies on cytokine effects in our experiments were usually performed after pretreatment with butyrate for two to four days, which should fairly resemble the exposure time to butyrate for enterocytes in vivo.

The effects of butyrate were studied in relation to both constitutive expression and cytokine mediated responses of various epithelial antigens with possible immune functions (for review, see reference 13): (a) transmembrane secretory component, a member of the immunoglobulin superfamily, ${ }^{20}$ is the poly-Ig receptor responsible for active transport of polymeric IgA and IgM into the gut lumen; (b) epithelial HLA class I molecules might present antigens to $\mathrm{CD8}^{+}$cytotoxic or suppressor T cells; (c) epithelial HLA class II molecules might present antigens to $\mathrm{CD}^{+}{ }^{+} \mathrm{T}$ cells and thereby induce or enhance activation in the gut; and (d) ICAM-1 is an adhesion molecule that may be required for activation of specific $T$ cells by antigen presenting epithelial cells. ${ }^{13} 16$ Epithelial expression of these proteins were quantified by modifications of a semiquantitative CELISA. ${ }^{1623} \mathrm{~A}$ standard curve was obtained on each microplate by growing strongly positive cells at different densities. This was particularly useful in these experiments because both butyrate itself and in 
combination with certain cytokines tended to inhibit growth rate, a variable that otherwise could have produced inconclusive data.

We found that butyrate increased the constitutive expression of secretory component and HLA class I proteins in a dose dependent manner, whereas the cells remained negative for ICAM-1 and HLA class II at moderate butyrate concentrations. Furthermore, butyrate enhanced stimulatory effects of most cytokines for all four antigens with two exceptions: TNF and IL 4 mediated stimulation of HLA class I and secretory component, respectively, was relatively suppressed by butyrate. These findings suggested that butyrate modulated these genes differentially. The corresponding mRNA concentrations were therefore analysed in control or cytokine stimulated cells; the constitutive messages for secretory component and HLA class I was virtually unaffected by butyrate alone, but mRNA for these two antigens as well as for ICAM-1 accumulated additively in combination with cytokines. TNF (alone or in combination with IFN) together with butyrate, however, resulted in a comparative reduction of both HLA class I and secretory component mRNA concentrations; the second actually showing a simultaneous increase in secretory component protein. These data suggested that butyrate uses complex mechanisms to regulate the transcription and protein synthesis of the respective genes and gene products in a differential manner.

It is still unclear how butyrate exerts its effects; its inhibition of histone deacetylase was initially taken to suggest that changes in chromatin structure and butyrate associated gene activation were caused by hyperacetylation of nuclear histones. ${ }^{12}$ More recent reports have considered the significance of butyrate sensitive specific gene elements near attachment regions to the nuclear matrix ${ }^{24}$ or specific $5^{\prime}$ flanking sequences in the promotor area that might mediate butyrate dependent gene regulation. ${ }^{25}$

Immunohistochemical data support that our model system reflects putative immunoregulatory mechanisms of the colonic epithelial cells in situ. ${ }^{13}$ However, it must be cautioned against extrapolation of such in vitro data based on a continuous cell line. Nevertheless, our results might imply that variations in the colonic flora with secondary changes in butyrate concentrations could influence the immunological properties of gut epithelial cells. For example, decreased faecal butyrate concentrations might tend to (a) increase expression of HLA class I, possibly rendering the epithelial cell a better target for $\mathrm{CD}^{+}$ intraepithelial $\mathrm{T}$ cells ${ }^{11}$; and (b) decrease secretory component expression, which in turn could result in less poly-Ig transport and thereby suboptimal protection of the mucosal surfaces. Furthermore, it might be expected that changed butyrate concentrations would significantly influence the cytokine mediated responses taking place in inflammatory gut lesions. In conclusion, our findings should encourage further studies of the interplay between the luminal bacterial flora, its fermentation products, and the mucosal immune system.

This work was supported by the Norwegian Cancer Society, the Norwegian Research Council, and Bruun's Legacy. We appreciate the help in computerised gene search by Dr K Taskén Institute of Medical Biochemistry, University of Oslo, valuable Institute of Medical Biochemistry, University of Oslo, valuable suggestions by Professor A Bjørneklett, Medical Department,
Regionsykehuset, Trondheim, and excellent technical assistance of L Mangschau, T Narvesen, and B Simonsen.

1 Wrong OM, Edmonds CJ, Chadwick VS. The large intestine: its role in mammalian nutrition and homeostasis. New York: John Wiley, 1981: 113-4.

2 Roediger WEW. Role of anaerobic bacteria in the metabolic welfare of the colonic mucosa in man. Gut 1980; 21 : 793-8.

3 Chapman MAS, Grahn MF, Boyle MA, Hutton M, Rogers $\mathrm{J}$, Williams NS. Butyrate oxidation is impaired in the colonic mucosa of sufferers of quiescent ulcerative colitis. Gut 1994; 35: 73-6.

4 Clausen MR, Mortensen PB, Holtug K, Nordgaard I, Hove H, Jessen PB. Kinetic studies on colonocyte metabolism of short-chain fatty acids and glucose in patients with ulcerative colitis. Gastroenterology 1994; 106: A666.

5 Vernia P, Gnaedinger A, Hauck W, Breuer RI. Organic anions and the diarrhea of inflammatory bowel disease. Dig Dis Sci 1988; 33: 1353-8.

6 Scheppach W, Sommer H, Kirchner T, Paganelli G-M, Bartram P, Christl S, et al. Effect of butyrate enemas on the colonic mucosa in distal ulcerative colitis. Gastroenterology 1992; 103: 51-6.

7 Harig JM, Soergel KH, Komorowski RA, Wood CM Treatment of diversion colitis with short-chain-fatty acid irrigation. N Engl f Med 1989; 320: 23-8.

8 Finnie IA, Taylor BA, Rhodes JM. Ileal and colonic epithelial metabolism in quiescent ulcerative colitis: increased glutamine metabolism in distal colon but no defect in butyrate metabolism. Gut 1993; 34: 1552-8.

9 Høverstad T, Carlsted-Duke B, Lingaas E, Midtvedt T, Norin KE, Saxerholt $\mathrm{H}$, et al. Influence of ampicillin, clindamycin, and metronidazole on faecal excretion of shortchain fatty acids in healthy subjects. Scand $\mathcal{F}$ Gastroenterol 1986; 21: 621-6.

10 Bennet JD, Brinkman M. Treatment of ulcerative colitis by implantation of normal colonic flora [letter]. Lancet 1989; i: 164.

11 Bowden TA, Mansberger AR, Lykins LE. Pseudomembranous enterocolitis: mechanism of restoring floral homeostasis. Am Surg 1981; 47: 178-83.

12 Kruh J. Effects of sodium butyrate, a new pharmacological agent, on cells in culture. Mol Cell Biochem 1982; 42: 65-82.

13 Brandzaeg P, Halstensen TS, Huitfeldt HS, Krajci P, Kvale $\mathrm{D}$, Scott $\mathrm{H}$, et al. Epithelial expression of HLA, secretory component (poly-Ig receptor), and adhesion molecules in the human alimentary tract. Ann NY Acad Sci 1992; 664: 157-79.

14 Sollid LM, Kvale D, Brandtzaeg P, Markussen G, Thorsby E. Interferon- $\gamma$ enhances expression of secretory component, the epithelial receptor for polymeric immunoglobulins. F Immunol 1987; 138: 4303-6.

15 Kvale D, Lovhaug D, Sollid LM, Brandtzaeg P. Tumor necrosis factor- $\alpha$ upregulates expression of secretory component, the epithelial receptor for polymeric immunoglobulins. F Immunol 1988; 140: 3086-9.

16 Kvale D, Krajci P, Brandtzaeg P. Expression and regulation of adhesion molecules ICAM-1 (CD54) and LFA-3 (CD58) in human intestinal epithelial cell lines. Scand $\mathcal{f}$ Immunol 1992; 35: 669-76.

17 Kvale D, Bartek J, Sollid LM, Brandtzaeg P. Rapid selection of cultured cells with increased expression of a membrane marker (secretory component). Int $\mathcal{f}$ Cancer 1988; 42: $638-41$.

18 Sambrook J, Fritsch EF, Maniatis T, eds. Molecular cloning. A laboratory manual. Cold Spring Harbor, NY: Cold Spring Harbor Laboratory Press, 1989.

19 Tanaka Y, Bush KK, Eguchi T, Ikekawa N, Taguchi T Kobayashi Y, et al. Effects of 1,25-dihydroxyvitamin D3 and its analogs on butyrate-induced differentiation of $\mathrm{HT}$ 29 human colonic carcinoma cells and on the reversal of the differentiated phenotype. Arch Biochem Biophys 1990; 276: 415-23.

20 Staunton DE, Marlin SD, Stratowa C, Dustin ML Springer TA. Primary structure of ICAM-1 demonstrates interaction between members of the immunoglobulin and intergrin supergene families. Cell 1988; 52: 925-33.

21 Augeron CA, Laboisse CL. Emergence of permanently differentiated cell clones in a human cancer cell line in culture after treatment with sodium butyrate. Cancer Res 1984; 44: 3961-9.

22 Krajci P, Kvale D, Taskén K, Brandtzaeg P. Molecular cloning and exon-intron mapping of the gene encoding the human transmembrane secretory component (poly-Ig receptor). Eur f Immunol 1992; 22: 2309-15.

23 Kvale D, Brandtzaeg P. Immune modulation of adhesion molecules ICAM-1 (CD54) and LFA-3 (CD58) in human hepatocytic cell lines. F Hepatol 1993; 17: 347-52.

24 Klehr D, Schlake T, Maass K, Bode J. Scaffold-attached regions (SAR elements) mediate transcriptional effects due to butyrate. Biochemistry 1992; 31: 3222-9.

25 Glauber JG, Wandersee NJ, Little JA, Ginder GD. 5 '-flanking sequences mediate butyrate stimulation of embryonic globin gene expression in adult erythroid cells. Mol Cell Biol 1991; 11: 4690-7. 